\title{
La construcción social del espacio regional transfronterizo
}

\section{The social construction of the cross-border regional space}

\author{
Valdez Gordillo, Mario E. (2006), Desencuentro y encuen- \\ tRo DE FRONTERAS: El PETÉN GUATEMALTECO Y El SURESTE MEXICANO \\ 1895-1949, UNIVERSIDAD INTERCULTURAL DE ChIAPAS-UNIVERSIDAD \\ de Ciencias y Artes de Chiapas, Tuxtla Gutiérrez, 322 pp., \\ ISBN: 968-5149-49-6.
}

\section{El marco analítico}

El trabajo que ofrece al público Mario Eduardo Valdez Gordillo es un ejercicio de historia regional comparada que nos muestra el complejo proceso de construcción de las fronteras, múltiples y diversas, en el establecimiento de los límites fronterizos México-Guatemala. En esta entrega abarca el periodo de 1895 a 1949 y queda comprometido a continuar con sus estudios para ofrecer una segunda parte en la que abordará el lapso de 1950 a 1996.

El caso particular que asombra al investigador es que el desarrollo de las localidades de la selva son, a la vez, las fronteras imaginadas para muy diversos actores que en la fragua de la explotación maderera y chiclera se apropiaban materialmente del territorio y sus recursos. También lo eran de las fronteras imaginadas que construían en sus proyectos de deslinde los Estadosnación y de los hombres fuertes que cimentaban sus redes de poder local y regional. La integración de esas nuevas zonas a la economía capitalista del sistema-mundo es -de la misma manera- determinante en la historia política para la conformación de poderes locales y regionales, así como para la historia diplomática y el establecimiento de los límites del Estado-nación mexicano y guatemalteco.

Las fronteras que presenta son el producto de una compleja articulación de relaciones sociales, políticas y económicas que se construyen en el proceso de apropiación del territorio. Es por ello que el autor prefiere hablar, más allá de las fronteras geopolíticas o de límites fronterizos, de la construcción de un espacio regional transfronterizo. 
En este libro el autor pretende rendir tributo a la corriente de la historiografía crítica que encuentra sus cimientos en la escuela de los Annales en la figura de Fernand Braudel, así como a la perspectiva del sistema-mundo que en la actualidad representa Immanuel Wallerstein, y ha sido impulsada entre los círculos académicos del sureste mexicano bajo el liderazgo de Carlos Antonio Aguirre Rojas. Pretende también que sea, al tiempo, un trabajo ilustrativo de las nuevas maneras de preguntarle a la historia.

La obra de Mario Eduardo Valdez muestra una historia regional bien lograda, toda vez que nos permite comprender un proceso complejo de integración y diferenciación territorial, de ocupación y devastación de espacios, pero también de su abandono, movidos por los intereses de actores sociales, los intereses de las empresas transnacionales y la transformación del gran capital y en el contexto de conformación de los límites del Estado-nación mexicano y guatemalteco.

En este sentido plantea fuertes críticas en contra de lo que califica como la historia positivista y oficial, tal como la ejercen Matías Romero y Daniel Cosío Villegas para el caso de la historia general de México y Jan de Vos, en el caso particular de la frontera México-Guatemala. Plantea como alternativa que el historiador debe preguntarse por el papel que juegan los sujetos históricos en la construcción de su propia historia y cómo se construye la historia desde abajo. Además ensaya con la historia autobiográfica para aclarar el proceso personal a través del cual surge la inquietud que le lleva a abordar este complejo fenómeno de la apropiación territorial transfronteriza.

El abordaje teórico-metodológico que propone el autor es complejo. Hace eco no sólo de trabajos antropológicos sobre la construcción de la frontera sur de México como los de Andrés Fábregas o los mejor conocidos del historiador Jan de Vos, también de estudios poco populares de historia económica como los de Cuauhtémoc González Pacheco.

Con la finalidad de abarcar y presentar las diversas historias posibles, se apoya en la metodología de la historia desde abajo propuesta por Jim Sharpe con la finalidad de comprender los móviles de los actores; se inserta en el análisis de los intereses económicos de diversos actores a través de los ciclos del capital transnacional en la selva chiapaneca y del Petén con la propuesta de Kondratieff.

También hace uso de las metodologías que aporta la etnohistoria para caracterizar a los agentes sociales que se mueven en 
los telones de la historia y destacan porque su actuación es definitoria en algunas coyunturas específicas. Además se inspira en la escuela de la geografía política crítica encabezada por Peter Tylor y Colin Flint en Inglaterra y Heriberto Cairo en España, como pertinentes para abordar la apropiación territorial, que crea localidades cruzadas por los intereses del capital global.

Sin embargo, esta compleja trama de modelos explicativos, fuentes teóricas y la revisión de la historia económica, política y diplomática, en algunos momentos resulta demasiado densa y con un ritmo de lectura que se torna dificultoso. Aunado a ello, los capítulos son demasiado extensos y se prestan a que el lector se sienta agobiado por la cantidad de temáticas abordadas, notas a pie de página y referencias cruzadas para abundar información en otros capítulos.

No obstante, vale la pena destacar, en descargo de lo anterior, que la obra se encuentra consistentemente documentada, tanto en fuentes primarias como secundarias, lo que demuestra el sólido oficio de historiador que posee el autor. Luego de cada capítulo se presentan anexos documentales, fotográficos y cartográficos que son útiles para seguir la pista de la compleja trama social que aborda el autor y pueden usarse con fines didácticos.

A partir de la existencia de fronteras naturales como un dato positivo, es decir, como un hecho, el autor se aboca con gran suficiencia de recursos teórico-metodológicos a documentar los procesos de construcción histórica del espacio regional transfronteri$z o$. Evidencia que las dinámicas tempranas del aprovechamiento de chicleros, xateros y monteros de los recursos de la selva generó lo que Doreen Massey denomina imaginación geográfica.

\section{El contenido de la obra}

El primer capítulo se titula "La frontera imaginada" y toma como punto de partida el acuerdo final de 1895 sobre límites internacionales entre los gobiernos de México y Guatemala que denomina una guerra de mapas. A diferencia de la historia aceptada en la que se pone énfasis en los intereses nacionales e inserta el conflicto limítrofe en la formación del Estado-nación mexicano y guatemalteco, el autor recorre los intrincados caminos de la diplomacia para aclarar y develarnos los intereses geopolíticos del capital trasnacional de empresas madereras que era protegidos desde la diplomacia y, a través de los representantes de 
ésta, reclamaban derechos territoriales en las selvas Lacandona y del Petén.

En este capítulo desmonta la idea de que la definición de la frontera es el resultado de los prístinos y muy patriotas intereses nacionales. A través de sus propias fuentes somete los datos encontrados y las fuentes ya referidas por otros autores a una nueva interpretación. El factor explicativo del famoso acuerdo final es la presencia de proyectos de explotación maderera y chiclera en una zona transfronteriza más amplia, que involucra a Chiapas y Tabasco en México, El Petén guatemalteco y alguna porción de Belice.

Abunda desde la historia económica en un complejo proceso de circulación monetaria, crediticia y de capitales que hacen posible la explotación de recursos es esas latitudes en las cuales no existían caminos ni infraestructura para tales fines. También analiza las políticas fiscal, financieras y hacendarias como factores a través de los cuales podemos entrever la integración de una zona nueva de explotación para la economía mundo. Estos factores son los que se muestran como el eje articulador de la construcción del espacio regional transfronterizo y en la definición de los límites internacionales entre México y Guatemala.

En el segundo acápite vincula la formación del espacio transnacional fronterizo con el papel que ciertos actores locales jugaron y que fue decisivo en la conformación del espacio regional, del manejo y aterrizaje de capitales. Al igual que trata de explicar la existencia de una estructura económica que se construye sobre la base de la frontera natural, el autor muestra la presencia de los hombres fuertes que construyen una red de alianzas políticas y una estructura de poder local y regional.

Caracteriza a los jefes políticos en dos tipos ideales dependiendo de la relación que guardan con los proyectos, tanto de los Estados-nación como del capital y las empresas trasnacionales: los trasnaempresarios y los protonacionalistas. Ambos desempeñan diversas funciones, desde militares hasta jurídicas y administrativas, y su desempeño será la clave de los destinos e influencia de los proyectos de explotación maderera y chiclera. Se vinculan con el capital mundial y establecen relaciones, ya conflictivas ya afables, con los sistemas estatales.

Este capítulo no se desliga de la estructura de la historia económica y de larga duración que el autor propone. Su explicación se sustenta en que para la incorporación de zonas nuevas al sistema-mundo es necesaria la presencia de un orden político-militar local y regional que se combina con la presencia de los Estados 
débiles. Ambos son factores para que la industria extractiva, necesariamente ligada al territorio, encuentre condiciones de arraigo y florecimiento.

El tercer capítulo vincula la historia regional a la historia económica. A partir de la existencia de recursos en la frontera natural, procede a documentar la explotación de dos productos en sus dimensiones espacio-temporal y económico-regional que nos explican, ambas, la construcción de las regiones de frontera. Se trata de la historia de la explotación del oro verde, la caoba, en Tabasco, Chiapas y El Petén y el oro blanco, el chicle, en El Petén.

Señala que cada producto en su espacio y tiempo muestra las fases de apropiación territorial, la fase de explotación intensiva y la introducción al mercado mundial hasta llegar a su ciclo de declinación. En el esquema explicativo del autor, siguiendo a Braudel, estos productos juegan un papel importante en los flujos históricos y muestran las fases cíclicas de expansión y estancamiento del capital. Los flujos de explotación de estos productos constituyeron regiones de frontera integradas en el esquema centro-periferia al sistema-mundo.

Los Estados-nación ensayaron diversas formas de apropiación del territorio, como el deslinde de terrenos baldíos -al mismo tiempo o en competencia- o cuando las empresas se habían retirado en la etapa de reflujo del capital. Asimismo, otros agentes se apropiaban del territorio de muy diversas maneras: por medio de los sistemas de contratación y acarreo de mano de obra, y mediante los sistemas de embarque y transporte de mercaderías y suministros a las monterías madereras y hatos chicleros que trasegaba hombres, dinero, técnicas de trabajo y mercancías entre El Petén guatemalteco, Belice y Chiapas y Tabasco en México.

Por último, en el cuarto capítulo el autor retoma la senda teorética para rearticular su explicación de la conformación del espacio regional transfronterizo, con sus muy diversos procesos de construcción de espacios en diferentes escalas, a partir de la geografía política y la economía mundo. Menciona que las diferentes líneas de desarrollo desigual en las selvas chiapaneca y petenera construyen una jerarquía de espacios a la que el autor denomina las localidades de la selva. Esas áreas remotas, ricas o pobres, que por alguna razón interesa su inserción a la economía mundo, mantienen sus procesos y características de periferia y avanzan o frenan su desarrollo bajo el influjo de los procesos del centro. 


\section{Las consecuencias extraídas del libro}

En esta obra encontramos, pues, la documentación de diversos intereses y la disputa entre diferentes proyectos de uso, apropiación y futuro para un mismo espacio. Esto es lo que el autor identifica como el proceso de construcción de una frontera imaginada compartida por los chiapanecos, los peteneros y los beliceños. Esa imaginación y las prácticas sociales de explotación de recursos hacen añicos el concepto construido con fines geopolíticos de frontera política construida de los Estado-nación. La inversión del capital transnacional es el motor para crear localidades en la selva donde dominen poderes regionales.

Desde luego, un fenómeno y otro (la conformación de límites fronterizos por razones geopolíticas, la transformación de la frontera natural y la construcción de fronteras imaginadas como producto de prácticas sociales y de inversión de capital, la construcción de localidades en la selva y de poderes políticos locales y regionales) se inscriben de manera compleja en diferentes temporalidades. El autor sigue con particular destreza el consejo de Braudel: ajustar los distintos tiempos históricos en la estructura explicativa de larga duración. Es por ello que el trabajo está organizado de manera temática y no temporal.

Sin duda alguna, el ensayo del maestro Valdez cumple su objetivo para mostrar el impacto del capital y de las empresas trasnacionales en la construcción de un espacio regional transfronterizo, y sólo resta esperar que se convierta en una obra de consulta para todos aquellos interesados en una historia compartida MéxicoGuatemala que ha sido poco explorada. También será una obra de referencia para los estudiosos de las regiones y las fronteras.

Recibido: 29 de mayo de 2007. Aceptado: 6 de julio de 2007.

LuIS RodRÍGUEZ-CASTILLO Universidad Nacional Autónoma de México lrodriguez@cmq.edu.mx

Luis Rodríguez Castillo. Es investigador asociado C de tiempo completo en el Programa de Investigaciones Multidisciplinarias sobre Mesoamérica y el Sureste, del Instituto de Investigaciones Antropológicas (Proimmse-IIA) de la Universidad Nacional Autó- 
noma de México (UNAM). Actualmente desarrolla el proyecto de investigación Procesos políticos, gestión local y pluralismo cultural en Las Margaritas, Chiapas, México (1970-2005). Una perspectiva antropológica de las políticas públicas, como parte de sus estudios de doctorado en ciencias sociales en El Colegio Mexiquense, A. C. Entre sus últimas publicaciones se encuentra la edición bilingüe tzeltal-español del libro Maravilla Tenejapa, Sk'op Ya'yejal JtejkLum, Conaculta-SEPI-CELALI-Gobierno del Estado de Chiapas, Tuxtla Gutiérrez (2006); en coautoría, "Espacios disputados y redes clientelares en la formación del municipio de Maravilla Tenejapa (región selva fronteriza)”, en Xóchitl Leyva y Araceli Burguete (coords.), La remunicipalización de Chiapas. La politica y lo político en tiempos de contrainsurgencia, CIESAs-Porrúa-Cámara de Diputados, México (2007); "Programa intermunicipal de inclusión escolar de menores entre 5 y 14 años en Chiapas” y, en coautoría, "Combate y protección contra incendios forestales en Villaflores, Chiapas", ambos en Tonatiuh Guillén López, Liliana González Pantoja y Pablo Rojo Calzada (coords.), Gobierno de proximidad. La capacidad y el ingenio de la gestión local mexicana, CIDE-INAFED-El Colegio de la Frontera Norte, México (2007); "Las disputas por autonomía y federalismo en la selva-fronteriza de Chiapas, México. Las secuelas de una remunicipalización fallida”, en Hirineo Martínez, Luis Ramírez, Héctor Raúl Solís y María Basilia Valenzuela (coords.), Creación de nuevos municipios en México. Procesos y perspectivas, Universidad de Guadalajara-El Colegio de Michoacán, Guadalajara (2007). 